\title{
Relationship Quality, Work-Family Stress, and Mental Health Among Australian Male Mining Industry Employees
}

\author{
Samara McPhedran and Diego De Leo \\ Australian Institute for Suicide Research and Prevention, National Centre of Excellence in Suicide Prevention \\ and World Health Organization Collaborating Centre for Research and Training in Suicide Prevention, Griffith \\ University, Brisbane, Queensland, Australia
}

\begin{abstract}
Australia is one of the world's foremost mining nations. While the economic and employment benefits of the mining industry are well documented, potentially negative aspects of mining industry employment are less understood. It has been suggested that mining industry workers may be more likely than workers in other occupations to experience relationship problems and work-family stress, but there is very little empirical study examining this proposal. Data from the nationally representative Household, Income, and Labour Dynamics in Australia (HILDA) survey were used to compare males employed in the Australian mining industry with males working in other occupations, on indices of relationship quality and work-family balance, as well as mental and emotional health. Employment in the resources sector was not associated with poorer outcomes on these measures, relative to other occupations. These results suggest that hypothesised connections between mining industry employment and relationship/family stress require careful examination.
\end{abstract}

- Keywords: occupation, relationships, stress

Australia is one of the world's foremost mining nations, with significant economic resources of brown coal, mineral sands (rutile and zircon), nickel, uranium, lead and zinc (Australian Bureau of Statistics, 2012a). The contributions of the mining industry to Australia's economy and employment are well documented, with statistical information readily available. For example, in 2009-2010, the mining industry was the fourth largest contributor to Australia's gross domestic product (GDP) with around $8 \%$ of total GDP, and mining businesses paid a total of $\$ 16.8$ billion in wages and salaries (Australian Bureau of Statistics, 2012a). In Australia's three major 'mining states' (Western Australia, Queensland, and New South Wales), mining industry employment grew relatively consistently from the late 1990s onward, and currently accounts for around $4 \%$ of the employed population (Australian Bureau of Statistics, 2012b).

Recently, interest has extended beyond statistical information about the number of people employed in mining towards possible negative psychosocial and communitylevel impacts of employment in that sector, and concern has been expressed about the wellbeing of mining industry workers (e.g., Commonwealth of Australia,
2013). The combination of often arduous conditions, geographic remoteness, and long working rosters associated with many types of mining may place miners at high risk of experiencing a range of social, psychological, and emotional challenges and stressors. Two interrelated areas that have received particular attention in popular debate are mental illness (especially depression and anxiety) and relationship/family stresses; these have, in turn, been suggested to contribute to an elevated risk of suicide among resources sector employees (see McPhedran \& De Leo, 2013, for a more detailed overview of this debate).

Although there exists considerable research into miners' physical health and workplace safety, speculation that miners may be at elevated risk of poor outcomes is not well supported by empirical evidence. There is very little Australian or international research into the psychological and emotional wellbeing of resources sector

ADDRESS FOR CORRESPONDENCE: Samara McPhedran, Level 1, M24 (Psychology), 176 Messines Ridge Rd, Mt Gravatt Campus, Griffith University, Mt Gravatt QLD 4122, Australia. Email: s.mcphedran@griffith.edu.au 
employees. In terms of quantitative studies into the psychosocial aspects of employment in the mining industry, there is scant available data to indicate whether or not mining does represent a 'high risk' industry for poor outcomes. These gaps in knowledge limit the ability of employers and policymakers to properly identify and respond to existing or emerging problems that may be faced by specific groups of workers.

\section{Mental Health and Resources Sector Work}

The limited amount of research into mental and/or emotional wellbeing and miners has produced mixed results. One study (van der Molen et al., 2012) found workers in mining and quarrying in the Netherlands had the second highest annual incidence of occupational illness per 100,000 worker years (second only to construction workers). While breakdowns of the types of illness per sector were not provided, mental illnesses were the most frequently recorded type of condition (van der Molen et al., 2012). In Australia, a qualitative study of $10 \mathrm{~min}$ ers found that those workers identified possible mental health concerns as part of their occupation, with particular mention of depression and stress (Mclean, 2012). Other sources, however, suggest that the prevalence of mental illness among mining workers is likely to be comparable with the community as a whole (NSW Minerals Council, 2012), and have found relatively low levels of mental stress claims in that industry (Australian Safety and Compensation Council, 2007). McPhedran and De Leo (2013) found no significant differences in psychiatric history between Australian miners and other men who died by suicide, suggesting that miners who took their own lives did not have a higher prevalence of mental illness relative to other men who died by suicide. However, this information was limited to a deceased sample, meaning that it could not examine whether living miners experienced more mental health problems than other workers.

In a further Australian study, Iverson and Maguire (2000) note that emotional isolation (in part relating to living in a remote location) was a key variable affecting life satisfaction among 286 male mining employees in a remote Queensland location. Although these findings are suggestive of connections between social and employment conditions associated with resources sector work and emotional functioning, the indicators used to assess affective states were limited in scope and depth. They consisted of one item concerning positive affect, and one item concerning negative affect.

An early study from the United Kingdom suggested that coal miners may experience greater 'emotional instability' relative to railway workers (Lion, 1960) and, more recently, some have proposed that 'emotional exhaustion' is a key issue impacting on miners' wellbeing, as well as their family relationships (Peetz, Murray, \& Muurlink,
2012). That suggestion is based on survey findings from a self-selected sample of 2,566 mining and energy workers and 1,915 partners of mining and energy workers. That study, while extending knowledge about a range of different aspects of employment in the mining and energy industries (such as satisfaction with working hours and rosters), nonetheless based its inferences about emotional functioning largely on response to items about workrelated fatigue. One item presented in the findings (' $\mathrm{I}$ am often so emotionally drained when I get home from work that it prevents me from contributing to my family') specifically considered emotional functioning and its connection with family relationships, thus a more comprehensive set of indicators would be desirable. Also, Peetz and colleagues (2012) exclusively considered mining and energy workers, and did not include a control sample drawn from a more general population. Consequently, conclusions cannot be drawn about whether mining and energy workers differ from workers in other sectors in terms of emotional function.

\section{Relationship/Family Stress and Resources Sector Work}

The possibility that employment in the resources sector may be associated with work-family stress and poor relationship quality outcomes relates largely to the long rosters, shift work, and (for non-resident or 'Fly In Fly Out' [FIFO] workers) lengthy absences from home common to many mining operations. Interpersonal relationships (including marital relationships and family functioning) can be disrupted by shift work (Presser, 2008; Simon, 1990) and the contribution of long working hours to 'work-family spillover' and associated stress has been very well documented internationally (e.g., Grzywacz, Almeida, \& McDonald, 2005; Grosswald, 2004; Hostetler, Desrochers, Kopko, \& Moen, 2012; Karimi, Karimi, \& Nouri, 2011; Lawson, Davis, Crouter, \& O’Neill, 2013; Odle-Dusseau, Britt, \& Bobko, 2012; Zolnierczyk-Zreda, Bedynska, \& Warszewska-Makuch, 2012). There is some evidence of this occurring among mining workers, but, again, existing empirical evidence is scarce and contains limitations. For example, Oldfield and Mostert (2007) found relationships between job demands, ill-health and work-home interference among South African miners, while Jacobs, Mostert and Pienaar (2008) showed that among a sample of 25 Afrikaans and Setswana mining workers, the consequences of work pressure, heavy workload, stress, and family obligations included a lack of quality time for self and family, physical and emotional strains, and low levels of productivity. However, given that workplace environments differ between countries, it is unclear whether such results can be generalised to other settings.

Torkington, Larkins, and Gupta's (2011) qualitative study of 11 FIFO mine workers in Charters Towers, Queensland, found that some workers identified 
work-life balance difficulties, including missing out on time with their children, feeling like an 'outsider' when they went home at the end of a work roster, and problems in their relationship with their partner (due in part to fatigue and disruptive or 'mismatched' routines). The findings provide a suggestive insight into mining workers' family relationships and certainly suggests that family difficulties may occur among some resources sector workers. Nonetheless, the study - being qualitative in nature contains the limitation of not providing robust, systematic data around family functioning. Kaczmarek, Sibbel, and Cowie (2003) also suggest that family stress may be higher among Australian FIFO families, relative to military families, and link this with frequent partner absence from home. A strength of that study was its inclusion of a control group (military families), but it is not certain whether the findings would be replicated if a more general control group drawn from a broader population (rather than the very specific population of military families) were used.

McPhedran and De Leo (2013) found that relationship problems prior to death by suicide were more commonly reported for men in the mining industry than for men in other occupations living in similar locations, but that study was unable to examine the prevalence of relationship problems in living mining workers relative to living workers in other occupations. It is possible, for example, that mining workers may experience higher levels of relationship problems overall than other workers, which could in turn explain the higher percentage of mining workers who had relationship problems prior to death by suicide (McPhedran \& De Leo, 2013). Alternatively, the prevalence of relationship problems may be comparable between living samples of miners and other workers (Clifford, 2009) or with the population as a whole (NSW Minerals Council, 2012), but may be more strongly associated with death by suicide among mining workers. That is, exposure to a stressful life event - relationship difficulties - may be comparable between groups, but the influence and impact of that event may differ between groups.

\section{Objectives of the Current Study}

To support policy and program development and healthy workforce design, it is necessary to conduct comparative, quantitative analysis of a living sample of workers employed in the mining industry with workers in other industries, to further investigate possible associations between resources sector work, mental wellbeing, and work-family issues. The current study used a nationally representative dataset to investigate whether men employed in the mining industry were more likely to experience poor mental health and relationship/workfamily balance problems, relative to men in other industries. The research also considered whether any observed differences between miners and men in other industries persisted when demographic and socioeconomic factors were taken into consideration.

\section{Methods}

\section{Data Source and Sample Selection}

All data were drawn from Wave 10 (2010) of the Household, Income and Labour Dynamics in Australia (HILDA) Survey (a self-report instrument). This is an extensively validated, widely used, and nationally representative panel dataset (for further information, refer to the Melbourne Institute HILDA Survey Technical and Discussion Papers series). It contains various scales and individual items assessing a wide range of variables across broad domains, including health, finances, employment circumstances, and interpersonal relationships. Workingage males (aged from 18 to 65 years) were selected for further analysis.

\section{Employment and Occupation}

Only men who were employed (full-time or part-time) were included in the sample. Men employed in mining were identified by combining two indicators contained in the HILDA survey: the Australian and New Zealand Standard Industrial Classification (ANZSIC; Australian Bureau of Statistics, 2006a) and the Australian and New Zealand Standard Classification of Occupation (ANZSCO; Australian Bureau of Statistics, 2006b). The ANZSIC was used to identify workers in the mining industry, and the ANZSCO was used to exclude clerical, administrative/other managerial, and human resources workers. This resulted in a combined variable that identified workers in the mining industry whose role was directly connected with the manual operation of mines (e.g., mining machine operators, plant operators, labourers, and machinists). These men were categorised as 'miners'. Men in other industries were categorised as 'other' workers.

The number of hours each individual reported working per week, on average, was also included in analyses. The total sample consisted of 375 employed, working-age males (66 miners and 309 men in other occupations).

\section{Demographic and Socioeconomic Variables}

Marital status was coded as married/de facto (referred to hereafter as 'partnered'), divorced/separated, never married and not living with someone in a relationship, or widowed. The highest education level attained by respondents was recoded into one of four categories: Year 11 or below, Year 12, Certificate/Diploma (excluding certificates/diplomas gained through tertiary study), and Tertiary. Respondents' number of resident children (aged 0 to 15 years) was also included in the analyses.

Two financial variables were assessed: equivalised household income (based on gross financial year income), and financial perception. Income, a continuous variable 
expressed in Australian dollars (Au\$), was equivalised using procedures described elsewhere (Australian Bureau of Statistics, 2003). The 'financial perception' item in HILDA (which asks individuals to rate on a 5-point scale how well they believe they and their family are faring financially, given their current needs and responsibilities) was recoded dichotomously $(0=$ reasonably comfortable to prosperous [doing well]), 1 = just getting along to very poor [doing poorly]).

The Socio-Economic Index for Areas (SEIFA; Australian Bureau of Statistics, 2001) relative advantage/disadvantage scale was included. The SEIFA advantage/disadvantage measure considers area characteristics, such as the proportion of families with a high income and proportion of people employed in a skilled occupation. The relative advantage/disadvantage index is a continuum on which lower scores indicate greater relative disadvantage and higher scores indicate greater relative advantage.

An additional location indicator was created for the study; whether or not a respondent's Statistical Local Area (SLA) contained at least one resources sector employee. This was used in conjunction with SEIFA to further control for possible location-related influences on results.

\section{Cultural Background}

Two indicators of cultural background were included: non-English speaking background (yes/no) and Aboriginal/Torres Strait Islander status (yes/no).

\section{Mental Health and Emotional Functioning}

Mental health, as well as emotional functioning, were assessed using subscales of the Short Form-36 (SF-36), a well-validated self-report measure covering physical, mental, and emotional health and functioning, over the 4 weeks prior to survey completion (Ware, Snow, Kosinski, \& Gandek, 1993). The SF-36 consists of 36 questions that sample eight dimensions of health (these dimensions are expressed as the subscales: physical functioning, role physical, bodily pain, general health, vitality, social functioning, role emotional, and mental health). Each dimension is scored on a scale ranging from 0 to 100 , with higher scores indicating better health/quality of life (Ware et al., 1993).

\section{Relationship Satisfaction and Relationship Transitions}

Two specific relationship satisfaction items from the HILDA life satisfaction scale were selected for analysis: the respondents' satisfaction with their relationship with their partner, and - given that relationship problems may extend beyond a partner to family more generally satisfaction with their relationship with their children. For each of these two items, responding persons were asked to rate their level of satisfaction using a Likert type scale, where 0 indicated completely dissatisfied and 10 indicated completely satisfied.
Life events that may indicate higher levels of poor relationship outcomes - such as separation - were considered using two relationship transition indicators that denoted the presence within the past 12 months of separation from a spouse, or reconciliation with a spouse.

\section{Work-Family Balance}

Work-family balance was assessed through a 16-question scale within HILDA. This self-report scale has been used in a number of studies into work-life balance (e.g., Losoncz, 2011). It requires participants to indicate their level of agreement with statements such as 'Because of the requirements of my job, I miss out on home or family activities that I would prefer to participate in', 'Because of the requirements of my job, my family time is less enjoyable and more pressured' and 'Because of my family responsibilities, the time I spend working is less enjoyable and more pressured'. Items are scored on a Likert type scale ranging from 1 (strongly disagree) to 7 (strongly agree).

\section{Analyses}

Demographic differences between occupation categories were assessed using family-wise chi-squared tests and independent samples $t$ tests as appropriate. For regression analyses, mental health, emotional functioning, relationship satisfaction, work-family balance, and separation and reconciliation were treated as separate variables. Two sets of regressions were performed for each variable: first, a bivariate comparison with occupation (mining/other) the only variable considered; and, second, multivariate analysis in which demographic and socioeconomic variables were controlled for. In the multivariate comparisons, all independent variables were entered in one step. A probability level of $p<.05$ was considered to be significant.

\section{Results}

Chi-squared tests comparing the proportion of partnered men in each occupation catgory indicated that mining employees were more likely to be married/living in a de facto relationship that men working in other industries, although this difference did not reach statistical significance at the family-wise level (mining: $77.3 \%$ married/defacto; other: $64.7 \%$ married/de facto; chi-square $=5.08 ; p=.17)$. This is consistent with McPhedran and De Leo's (2013) finding that adult male mining workers who died by suicide were more likely to be partnered than men in other occupations, but again, not at a statistically significant level. There were no differences in the proportion of men who were divorced/separated, single/never married, and widowed.

The final sample, which included partnered working age men only, consisted of 249 respondents. Of these, $51(20.5 \%)$ were employed in the mining industry, with 


\section{TABLE I}

Descriptive Data: Demographics and Socioeconomics

\begin{tabular}{|c|c|c|c|c|}
\hline & Mining & Other & & \\
\hline & $n(\%)$ & $n(\%)$ & $\chi^{2}$ & $P$ value \\
\hline Age & $\begin{array}{l}\text { Mean: } 39.4 \\
(S D: 10.8)\end{array}$ & $\begin{array}{l}\text { Mean: } 42.7 \\
\text { (SD: } 12.2)\end{array}$ & $t=\mathrm{I} .74$ & .08 \\
\hline \multicolumn{5}{|l|}{ Highest education level } \\
\hline Tertiary & $3(5.9)$ & $38(19.2)$ & 5.64 & .13 \\
\hline Certificate/Diploma & $30(58.8)$ & $92(46.5)$ & & \\
\hline Year 12 & $6(11.8)$ & $23(11.6)$ & & \\
\hline Less than Year 12 & $12(23.5)$ & $45(22.7)$ & & \\
\hline \multicolumn{5}{|l|}{ Number of children } \\
\hline 0 & $25(49.0)$ & $107(54.0)$ & 1.72 & .42 \\
\hline I & $8(15.7)$ & 39 (19.7) & & \\
\hline $2+$ & $18(35.3)$ & $52(26.3)$ & & \\
\hline Non-English speaking background & $0(0.0)$ & $15(7.6)$ & 4.11 & .04 \\
\hline Aboriginal/Torres Strait Islander & I (2.0) & $2(1.2)$ & ^ & 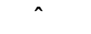 \\
\hline Hours worked per week & $\begin{array}{l}\text { Mean: } 5 \mathrm{I} .1 \\
(S D: 13.1)\end{array}$ & $\begin{array}{l}\text { Mean: } 42.7 \\
(S D: 12.4)\end{array}$ & $t=4.17$ & $<.01$ \\
\hline Equivalised income $\$ A U$ (Financial year) & $\begin{array}{l}\text { Mean: } 79,048 \\
\text { (SD: } 26,546)\end{array}$ & $\begin{array}{l}\text { Mean: } 68,319 \\
\text { (SD: } 59,378)\end{array}$ & $t=1.26$ & .21 \\
\hline \multicolumn{5}{|l|}{ Perceived financial wellbeing } \\
\hline Doing well & $4 \mathrm{I}(80.4)$ & $138(70.1)$ & 2.16 & .14 \\
\hline Doing poorly & $10(19.6)$ & $59(29.9)$ & & \\
\hline SEIFA & $\begin{array}{l}\text { Mean: } 992.4 \\
\text { (SD: } 69.8)\end{array}$ & $\begin{array}{l}\text { Mean: 991.6 } \\
\text { (SD: } 90.2)\end{array}$ & $t=.06$ & .95 \\
\hline
\end{tabular}

Note: Percentages calculated on the basis of cases where information was available. Percentages may not sum to 100 due to rounding error. ^ not further analysed due to insufficient sample size.

the remaining 198 (79.5\%) employed in other industries. Table 1 provides descriptive information.

\section{Mental Health and Emotional Functioning, Relationship Satisfaction and Work-Family Balance}

Table 2 provides descriptive statistics for mental health, emotional functioning, relationship satisfaction, and work-family balance variables. The latter scale was found to have acceptable inter-item reliability, with a Cronbach's coefficient alpha of 0.73 . The two groups were comparable across all indicators, with the exception of the workfamily balance item 'Because of my family responsibilities, I have to turn down work activities or opportunities that I would prefer to take on', on which mining workers had lower levels of work-family tension.

\section{Relationship Transitions}

During the 12 months prior to being surveyed, no mining workers, and one other worker $(0.5 \%)$ had reconciled with a spouse. No respondents indicated any epoch of separation during the 12-month study period. Given the infrequency of reported relationship transitions that may indicate poor relationship outcomes, these two items were not further analysed.

\section{Regression Analyses}

Table 3 summarises associations between occupation and mental health and emotional functioning, relationship satisfaction, and work-family balance indicators. Coefficients are for occupation category only (coefficients for other independent variables are not shown). 'Other occupation' was set as the reference category.

There were few associations between occupation and indices of mental and emotional wellbeing, relationship quality, and work-family balance. The only statistically significant associations were found on the work-family balance variables of 'having to turn down work opportunities' (where mining was associated with lower levels of agreement with this response) and 'better appreciate time spent with children' (where mining industry employment was associated with higher levels of appreciation of time with children), using multivariate analyses.

Of the range of independent variables used in the multivariate analyses, one indicator in particular - a perception of 'doing poorly' financially — deserves mention. This indicator was associated with a number of variables of interest. These were: lower emotional functioning and mental health, and higher likelihood of feeling that time spent working was less enjoyable/more pressured, missing out on home/family activities, worrying about children while at work, having too little time or energy to be an aspirational parent, missing rewarding aspects of being a 
TABLE 2

Descriptive Data: Mental Health and Emotional Functioning, Relationship Satisfaction and Work-Family Balance

\begin{tabular}{|c|c|c|}
\hline & Mining & Other \\
\hline & Mean (SD) & Mean (SD) \\
\hline \multicolumn{3}{|l|}{ Mental and emotional wellbeing } \\
\hline Mental health & $79.1(12.4)$ & $76.7(15.4)$ \\
\hline Emotional functioning & $96.7(15.3)$ & $90.5(24.8)$ \\
\hline \multicolumn{3}{|l|}{ Relationship quality } \\
\hline Relationship satisfaction - partner & $8.7(1.5)$ & $8.5(1.6)$ \\
\hline Relationship satisfaction - children & $7.9(2.3)$ & $8.0(1.9)$ \\
\hline \multicolumn{3}{|l|}{ Work-family balance } \\
\hline Work makes me a more rounded person & $5.4(1.0)$ & $5.3(\mathrm{I} .3)$ \\
\hline Work gives my life more variety & $5.3(0.9)$ & $5.3(1.3)$ \\
\hline Work makes me feel competent & $5.1(0.9)$ & $5.1(1.3)$ \\
\hline Have to turn down work/opportunities & $2.4(1.4)$ & $3.1(1.6)^{*}$ \\
\hline Having both work and family responsibilities challenges me to be the best I can be & $5.2(1.0)$ & $4.9(1.4)$ \\
\hline Time working less enjoyable/more pressured & $2.9(\mathrm{I} .6)$ & $3.2(1.6)$ \\
\hline Miss out on home/family activities & $4.8(1.6)$ & $4.3(1.9)$ \\
\hline Family time less enjoyable/more pressured & $3.5(1.5)$ & $3.3(1.6)$ \\
\hline Working makes me feel good about myself, which is good for my children & $5.2(1.3)$ & $5.1(1.3)$ \\
\hline My work has a positive effect on my children & $4.8(1.3)$ & $4.8(1.4)$ \\
\hline Better appreciate time spent with children & $5.7(1.1)$ & $5.2(1.3)$ \\
\hline Working makes me a better parent & $5.2(1.5)$ & $4.7(1.5)$ \\
\hline Worry about children while at work & $3.9(2.1)$ & $3.7(1.8)$ \\
\hline Too little time or energy to be aspirational parent & $3.7(1.6)$ & $3.8(1.8)$ \\
\hline Miss out on the rewarding aspects of being parent & $4.8(1.6)$ & $4.4(1.9)$ \\
\hline Thinking about the children interferes with my performance at work & $2.5(\mathrm{I} . \mathrm{I})$ & $2.4(\mathrm{I} .4)$ \\
\hline
\end{tabular}

Note: ${ }^{*} p<.05$

parent, and reporting that thinking about children while at work interferes with work performance.

In addition, the average number of hours spent working per week was independently associated with lower relationship satisfaction with both partner and children, higher likelihood of reporting too little time or energy to be an aspirational parent, lower reported appreciation of time spent with children, and higher levels of self-reported interference with work performance due to thinking about children.

To consider possible influences on the results of covariance between hours worked and income obtained, two permutations of the regression model were tested: one in which hours worked was removed, and one in which income was removed. These variations did not change any of the results obtained.

\section{Discussion}

These quantitative results build on the very limited amount of evidence currently available about the psychosocial aspects of work in the Australian mining industry, providing the first comparative study of mental health, emotional functioning, and levels of relationship/family stress among male mining workers. The findings do not provide support for the hypothesis that resources sector employment is associated with greater relationship/work-family stress, or with poorer mental and emotional health, relative to employment in other occupations.

There were very few differences between outcomes on these variables for miners relative to working age men in other occupations. In the small number of instances where associations were found between occupation type and indices of wellbeing and family functioning, employment in mining was not shown to be associated with poorer outcomes. While appropriate caution should be applied given the relatively small number of miners in the sample, these findings nonetheless suggest that hypothesised connections between mining industry employment and relationship/family stress, as well as mental and emotional health, require careful examination.

The results do provide tentative support for one aspect of the theorised relationship between mining sector work and certain relationship/family stressors. Notably, men employed in the resources sector worked longer hours, on average, than men in other occupations, and longer working hours were independently associated with lower perceived relationship quality (with both spouse and children) as well as three measures of workfamily stress. This is consistent with observations about work characteristics and work-family balance (e.g., Grosswald, 2004; Grzywacz, Almeida, \& McDonald, 2005; Hostetler, Desrochers, Kopko, \& Moen, 2012; Karimi et al., 2011; Lawson et al., 2013; Odle-Dusseau et al., 2012; Zolnierczyk-Zreda et al., 2012). While occupation 


\section{TABLE 3}

Associations Between Occupation and Mental Health, Emotional Functioning, Relationship Quality, and Work-Life Balance

\begin{tabular}{lrr}
\hline & Bivariate & Multivariate \\
\cline { 2 - 3 } & \multicolumn{1}{l}{$\beta$} & $\beta$ \\
\hline Mental and emotional wellbeing & & \\
Mental health & 5.62 & 0.17 \\
Emotional functioning & 3.55 \\
Relationship quality & 0.31 & 0.18 \\
Relationship satisfaction - partner & -0.10 & 0.05 \\
Relationship satisfaction - children & & \\
Work-family balance & 0.22 & 0.31 \\
Work makes me a more rounded person & 0.03 & 0.15 \\
Work gives my life more variety & 0.00 & 0.12 \\
Work makes me feel competent & $-0.59^{*}$ & $-0.66^{*}$ \\
Have to turn down work/opportunities & 0.21 & 0.23 \\
Having both work and family responsibilities challenges me to be the best I can be & -0.19 & -0.13 \\
Time working less enjoyable/more pressured & 0.62 & 0.60 \\
Miss out on home/family activities & 0.32 & 0.29 \\
Family time less enjoyable/more pressured & -0.05 & 0.04 \\
Working makes me feel good about myself, which is good for my children & -0.11 & -0.02 \\
My work has a positive effect on my children & 0.40 & $0.64^{*}$ \\
Better appreciate time spent with children & 0.38 & 0.54 \\
Working makes me a better parent & 0.30 & 0.56 \\
Worry about children while at work & 0.00 & -0.19 \\
Too little time or energy to be aspirational parent & 0.53 & 0.31 \\
Miss out on the rewarding aspects of being parent & 0.03 & -0.04 \\
Thinking about the children interferes with my performance at work & & \\
\hline
\end{tabular}

Note: ${ }^{*} p<.05$.

was not, in itself, associated with these variables, it is plausible that the amount of variance observed among mining sector employees' responses may indicate the presence of distinct subgroups of mining workers - for instance, those who work extremely long hours and experience high relationship/family stress, and those who work fewer hours and experience little or no stress. This possibility merits further consideration, as it may relate to mining employees' specific modes of work (e.g., rotating shifts vs. set schedules, or residential vs. FIFO), which in turn has implications for workforce design and family policies.

'Doing poorly' financially was associated with poor mental and emotional wellbeing, and greater work-family stress. Although the differences were not statistically significant, mining employees had higher average equivalised income and a lower likelihood of 'doing poorly' financially, relative to workers in other occupations. Therefore, although long working hours may impact on wellbeing and family functioning, it is also possible that any negative impacts of long hours on mining industry employees may be partially mitigated or 'offset' by the financial rewards associated with resources sector employment (Australian Bureau of Statistics, 2012c) and lower levels of financial stress (which is, in itself, a risk factor for suicidal behaviour; see Wang et al., 2012). While analysis of mediating and moderating factors surrounding wellbeing and work-life balance among miners was outside the scope of the current study, this represents an important direction for future research.

An important point is that this investigation was limited to men living in 'an area containing a miner'; this method was deliberately used to capture 'mining communities', to reduce the likelihood of locational influences on results obtained. It could be argued that this represents a weakness in study design, because it excludes a geographically diverse sample of working-age men — a more 'general' population. Indeed, it is fair to speculate that both men employed in the resources sector and men employed in different industries, but living in the same locations as mining employees, may experience poorer wellbeing and greater relationship and family stresses than men in other locations. However, this would indicate an influence of location, rather than occupation; this question is being investigated in work currently underway.

The current results do not provide strong evidence for an association between employment in the resources sector and relationship breakdown or poor relationship quality. The proportion of divorced/separated men did not differ by occupation, and, among partnered men, occupation was not associated with differences in the occurrence of separation/reconciliation, or differences in relationship quality with a partner or with children. This suggests that the greater frequency of relationship problems prior to death that was observed among deceased 
mining workers relative to other workers who died by suicide (McPhedran \& De Leo, 2013) is unlikely to be due to employees in the resources sector having a higher frequency of relationship problems in general.

Potentially, this may indicate that men in mining occupations who experience relationship stress may - for reasons that are not yet clear - be especially vulnerable to poor outcomes, including in extreme instances, suicide. Alternatively, it may suggest that there is a subset of resources sector employees who experience a range of 'shared' risk factors for both relationship stress and suicide. The possible presence of general risk factors may not have been readily detected by the current study, given that its specific focus was on relationship and family functioning in a living sample, rather than broader factors that may contribute to suicidal behaviour.

A limitation of this study was that it did not take into account the possibility of 'self-selection' into, and out of, the mining worker sample. It is possible that workers who enter the mining industry, and who begin to experience stresses associated with that work, may selfselect out of the industry before those stresses exceed their coping abilities and lead to relationship or other problems. Conversely, persons who remain in the mining industry may be more likely to possess characteristics or traits that are protective against poor outcomes. Using the longitudinal nature of the HILDA survey, this question will be explored in more depth in subsequent papers.

Based on observations from the current study, it appears that resources sector employment overall may not be associated with poorer outcomes for workers, relative to workers in other sectors. However, on the basis of other studies into situational influences on workers' wellbeing (e.g., Peetz et al., 2012; Zolnierczyk-Zreda et al., 2012), it is possible that there are within-sample differences in worker characteristics that may be associated with poor outcomes for certain subsets of resources sector (or, indeed, other) workers - for example, differences in work patterns and schedules. Exploring this possibility was not the purpose of the current study; however, an important future direction for research is to consider in more detail the individual characteristics of miners, and possible associations between different 'modes' of work (such as rotating shifts and long working rosters) and psychosocial outcomes among resources sector employees.

In summary, the current research suggests that employment in the Australian mining industry does not appear, in and of itself, to be associated with higher levels of relationship/work-family stress relative to employment in other occupations, among working-age men living in similar locations. In relation to observations about the possible contribution of relationship problems to suicide in the mining industry in one Australian jurisdiction (McPhedran \& De Leo, 2013), which could have been interpreted as providing evidence of higher relationship problems within the resources sector, the current study using a nationwide living sample provides initial evidence that the higher frequency of relationship problems among men in the mining industry who died by suicide seems unlikely to be explained by higher levels of relationship stressors within that sector overall.

\section{Acknowledgments}

This article uses unit record data from the Household, Income and Labour Dynamics in Australia (HILDA) Survey. The HILDA Project was initiated and is funded by the Australian Government Department of Families, Housing, Community Services and Indigenous Affairs (FaHCSIA) and is managed by the Melbourne Institute of Applied Economic and Social Research (Melbourne Institute). The findings and views reported in this article, however, are those of the authors and should not be attributed to either FaHCSIA or the Melbourne Institute.

\section{References}

Australian Bureau of Statistics. (2001). ABS view on remoteness (Cat. no. 1244.0). Canberra, Australia: Author.

Australian Bureau of Statistics. (2003). Household income and income distribution (Cat. no. 6523.0). Canberra, Australia: Author.

Australian Bureau of Statistics. (2006a). Australian and New Zealand standard industrial classification (Cat. no. 1292.0). Canberra, Australia: Author.

Australian Bureau of Statistics. (2006b). Australian and New Zealand standard classification of occupations (Cat. no. 1220.0). Canberra, Australia: Author.

Australian Bureau of Statistics. (2012a). Year book Australia (Cat. no. 1301.0). Canberra, Australia: Author.

Australian Bureau of Statistics. (2012b). Labour force, Australia, May 2012 (Cat. no. 6202.0). Canberra, Australia: Author.

Australian Bureau of Statistics. (2012c). Average weekly earnings, Australia (Cat. no. 6302.0). Canberra, Australia: Author.

Australian Safety and Compensation Council. (2007). Compendium of workers' compensation statistics Australia 2004-05. Canberra, Australia: Author.

Clifford, S. (2009). The effects of fly-in/fly-out commute arrangements and extended working hours on the stress, lifestyle, relationship and health characteristics of Western Australian mining employees and their partners: report of research findings. Unpublished report, University of Western Australia, Australia.

Commonwealth of Australia. (2013). Cancer of the bush or salvation for our cities? Fly-in, fly-out and drive-in, drive-out workforce practices in Regional Australia. Canberra, Australia: House of Representatives Standing Committee on Regional Australia.

Grosswald, B. (2004). The effects of shift work on family satisfaction. Families in Society, 85(3), 413-423.

Grzywacz, J.G., Almeida, D.M., \& McDonald, D.A. (2005). Work-family spillover and daily reports of work and family stress in the adult labor force. Family Relations, 51, 28-36.

Hostetler, A., Desrochers, S., Kopko, K., \& Moen, P. (2012). Marital and family satisfaction as a function of work demands and community resources: Individual and couple-level analyses. Journal of Family Issues, 33(3), 316-340. 
Iverson, R.D., \& Maguire, C. (2000). The relationship between job and life satisfaction: Evidence from a remote mining community. Human Relations, 53(6), 807-839.

Jacobs, D., Mostert, K. \& Pienaar, J. (2008). Experience of worklifeinteraction in the mining industry: A phenomenological study. South African Journal of Economic and Management Sciences, 11(1), 17-36.

Kaczmarek, E.A., Sibbel, A.M., \& Cowie, C. (2003). Australian military and Fly-In/Fly-Out (FIFO) mining families: A comparative study. Australian Journal of Psychology - Supplement 2003, 187-188.

Karimi, L., Karimi, H., \& Nouri, A. (2011). Predicting employees' well-being using work-family conflict and job strain models. Stress and Health, 27(2), 111-122.

Lawson, K., Davis, K, Crouter, A., \& O’Neill, J. (2013). Understanding work-family spillover in hotel managers. International Journal of Hospitality Management, 33, 273-281.

Lion, J.S. (1960). A comparison of the emotional stability of coalminers and railwaymen. British Journal of Industrial Medicine, $17,41-45$.

Losoncz, I. (2011). Persistent work-family strain among Australian mothers. Family Matters, 86, 79-88.

Mclean, K. (2012). Mental health and well-being in resident mine workers: Out of the fly-in fly-out box. Australian Journal of Rural Health, 20, 126-130.

McPhedran, S., \& De Leo, D. (2013). Suicide among miners in Queensland, Australia: A comparative analysis of demographics, psychiatric history and stressful life events. SAGE Open, October-December 2013, 1-9. doi:10.1177/2158244013511262.

NSW Minerals Council. (2012). Mental health and the NSW minerals industry. Sydney: Australia.

Odle-Dusseau, H., Britt, T., \& Bobko, P. (2012). Work-family balance, well-being, and organizational outcomes: Investigat- ing actual versus desired work/family discrepancies. Journal of Business and Psychology, 27(3): 331-343.

Oldfield, G., \& Mostert, K. (2007). Job characteristics, ill health and negative work-home interference in the mining industry. SA Journal of Industrial Psychology, 33(2), 68-75.

Peetz, D., Murray, G., \& Muurlink, O. (2012). Work and hours amongst mining and energy workers: Australian coal and energy survey first phase report. Griffith University, Brisbane: Australia.

Presser, H. (2000). Non standard work schedules and marriage instability. Journal of Marriage and the Family, 62, 93110.

Simon, B.L. (1990). Impact of shift work on individuals and families. Families in Society: The Journal of Contemporary Social Services, 71(6), 342-348.

Torkington, A.M., Larkins, S., \& Gupta, T.S. (2011). The psychosocial impacts of fly-in fly-out and drive-in drive-out mining employees: a qualitative study. Australian Journal of Rural Health, 19, 135-141.

van der Molen, H.F., Kuijer, P.P.F.M., Smits, P.B.A., Schop, A., Moeijes, F., Spreeuwers, D., \& Frings-Dresen, M.H.W. (2012). Annual incidence of occupational diseases in economic sectors in the Netherlands. Occupational and Environmental Medicine, 69, 519-521.

Wang, Y., Sareen, J., Afifi, T., Bolton, S-L., Johnson, E., \& Bolton, J. (2012). Recent stressful life events and suicide attempt. Psychiatric Annals, 42(3), 101-108.

Ware, J.E., Snow, K.K., Kosinski, M., \& Gandek, B. (1993). SF-36 Health Survey Manual and Interpretation Guide. Boston, MA: New England Medical Center.

Zolnierczyk-Zreda, D., Bednyska, S., \& Warszewska-Makuch, M. (2012). Work time control and mental health of workers working long hours: The role of gender and age. International Journal of Occupational Safety and Ergonomics, 18(3), 311320. 